\title{
Perancangan Sistem Informasi Akademik Pada Sekolah Menengah Pertama Berbasis Web
}

\author{
Ela Nurelasari \\ Program Studi Sistem Komputer, Fakultas Teknik dan Informatika, Universitas Bina Sarana Informatika \\ Jl. Kamal Raya No. 18, Ringroad Barat, Cengkareng, Jakarta Barat \\ *email:ela.eur@bsi.ac.id
}

(Naskah masuk: 03 Oktober 2019; diterima untuk diterbitkan: 29 Januari 2020)

\begin{abstract}
ABSTRAK - Teknologi informasi melaju dengan cepatnya. Adapun komputer yang merupakan peralatan yang diciptakan untuk mempermudah pekerjaan manusia, saat mencapai kemajuan baik di dalam pembuatan hardware maupun software. Teknologi komputer sangat mendukung dalam hal pengolahan data untuk membuat suatu sistem informasi yang digunakan agar memberikan suatu hasil kerja yang maksimal. Perkembangan teknologi informasi dipengaruhi juga oleh internet. Dengan internet kita dapat memberikan pelayanan dengan mudah yang dapat diakses dari mana saja didunia ini. Sekarang ini, hampir semua orang dapat mengakses informasi, salah satunya melalui website di internet. Dengan menggunakan sistem informasi akan dengan mudah mendapatkan informasi yang dibutuhkan. Sistem informasi akademik sekolah menengah pertama adalah salah satu sistem akademik yang sangat penting untuk semua informasi-informasi kegiatan yang ada di sekolah. Maksud dan tujuan dari dibuatnya website tersebut adalah untuk menyediakan sistem pendaftaran siswa baru yang terkomputerisasi, dapat memudahkan siswa untuk melihat nilai hasil belajar tanpa datang ke sekolah dan memudahkan guru-guru dalam penginputan nilai siswa.
\end{abstract}

Kata Kunci - Sistem Informasi Akademik, Waterfall, ERD, LRS, Blackbox Testing.

\section{Academic Information System Design in Web-Based Middle School}

\begin{abstract}
Information technology is advancing rapidly. The computer which is equipment that was created to facilitate human work, when achieving progress both in making hardware and software. Computer technology is very supportive in terms of data processing to create an information system that is used to provide maximum work results. The development of information technology is also influenced by the internet. With the internet we can provide services easily that can be accessed from anywhere in the world. Nowadays, almost everyone can access information, one of them through websites on the internet. By using information systems will easily get the information needed. Junior high school academic information system is one academic system that is very important for all information activities in school. The purpose and purpose of making the website is to provide a computerized new student registration system, can make it easier for students to see the value of learning outcomes without coming to school and make it easier for teachers to input student grades.
\end{abstract}

Keywords - Academic Information Systems, Waterfall, ERD, LRS, Blackbox Testing.

\section{Pendahuluan}

Teknologi Komputer dibutuhkan oleh banyak orang dalam perkembangan sistem pemrosesan. Teknologi komputer sangat mendukung dalam hal pengolahan data untuk membuat suatu sistem informasi yang digunakan agar memberikan suatu hasil kerja yang maksimal [1]. Informasi adalah data yang telah diproses sehingga memiliki arti dan nilai kepada penerima informasi tersebut [2]. Kualitas informasi adalah ketepatan waktu, keakuratan, relevansi dan kemudahan untuk memperolehnya[3]. Hal tersebut dibuktikan dengan terkomputerisasinya di segala bidang. Contohnya bidang ekonomi, sosial, pendidikan, politik, kebudayaan, kesehatan, administrasi, dan lembaga-lembaga pemerintah maupun swasta. Sekolah sebagai salah satu bentuk organisasi merupakan pelaksana teknis pendidikan 
formal di lingkungan pendidikan nasional. Dalam Struktur organisasi sekolah bisa menunjukan hubungan antara kepala sekolah, guru, siswa dan karyawan serta pihak lainnya di luar sekolah. Mayoritas di sekolah dalam olahan data akademik masih dikerjakan dengan cara mencatat secara manual. Padahal kebutuhan siswa, orang tua siswa, dan masyarakat umum akan informasi akademik sekolah semakin meningkat. Akibatnya terjadi keterlambatan arus informasi karena pekerjaan yang dikerjakan kurang efisien dan tidak update, selain itu rawan terjadinya kerusakan dan duplikasi data sehingga informasi yang didapat tidak valid. Untuk itu dibutuhkan suatu sistem informasi akademik yang dapat memberikan informasi secara Online baik terhadap pihak sekolah, siswa, wali murid ataupun masyarakat luas. Selain itu mampu melakukan pengolahan data akademik secara efektif dan efisien [4]. Kesimpulannya bahwa sistem informasi sangat diperlukan bagi dunia pendidikan terkhusus mengenai akademik kesiswaan[5]. Sistem informasi akademik dapat memberikan manfaat kepada guru dan siswa dalam mendapatkan informasi-informasi akademik [6].

Adanya kekurangan dalam sistem di tingkat sekolah menengah pertama (SMA) yang seharusnya bisa lebih berkembang. Terutama pada sistem pendidikannya, masih banyak sekolah yang menggunakan sistem manual dalam proses memasukkan data nilai yang dapat mengakibatkan terjadinya kerusakan data dan beberapa sekolah menengah pertama pun belum diketahui oleh masyarakat. Oleh sebab itu, dibutuhkan sebuah fasilitas sekolah yang bisa mempermudah siswa, guru, staff serta masyarakat [7].

Salah satu permasalahan yang sering timbul dalam sistem manual adalah proses penilaian yang dilakukan oleh guru cenderung memakan waktu lama. Setelah memeriksa jawaban ujian siswa, guru harus membuat nilai akhir ujian. Kegiatan pengalkulasian nilai final ujian tersebut menjadi tidak efektif karena proses pengerjaan membutuhkan waktu yang cukup lama untuk dapat mengetahui nilai ujiannya [8].

Sistem Informasi administrasi akademik dapat mempermudah proses kinerja pendidikan, lebih efektif, meningkatkan produktifitas pendidikan menjadi lebih efektif dan memudahkan dalam pengoperasian pendidikan [9]. Sistem informasi merupakan suatu sistem berada pada organisasi dimana mempertemukan antara kebutuhan pengelolaan dari suatu organisasi serta menyiapkan laporan-laporan yang dibutuhkan bagi pihak luar [10]. Guru bisa memberikan pelayanan tanpa harus berhadapan langsung dengan siswa dengan menggunakan e-learning pada saat ini,. Demikian pula siswa memperoleh informasi dari berbagai sumber melalui internet [11].

Oleh karena itu, dengan adanya sebuah program yang mendukung kebutuhan tersebut, diharapkan dapat memberikan suatu wadah yang dapat memberikan informasi akademik dengan mudah, cepat dan akurat. Selain itu mampu melakukan pengolahan data akademik secara efektif dan efisien[4].

\section{METODE DAN BAHAN}

Dalam usaha pengumpulan data, metode yang digunakan adalah metoda pengembangan perangkat lunak dan metoda pengambilan data.

\subsection{Metode Pengembangan Perangkat Lunak}

Metode yang digunakan pada pengembangan perangkat lunak ini menggunakan model water fall. Model air terjun sering juga disebut model sekuensial linier disebut juga alur hidup klasik (classic life sycle) [12]. Model SDLC air terjun (waterfall). Model SDLC Perangkat lunak dimulai dari analisa kebutuhan, desain perangkat lunak, pengkodean program, pengujian atau testing program, dan tahap pendukung (support) atau pemeliharaan(maintenance) seperti yang ditunjukkan pada gambar 1 .

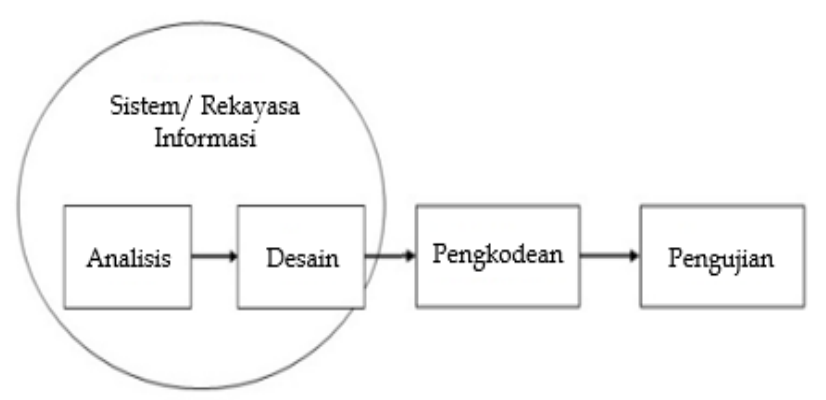

Gambar 1. Model air terjun (Waterfall)

Tahapan-tahapan waterfall model adalah sebagai berikut:

a. Analisa kebutuhan perangkat lunak

Pada proses ini melakukan pengumpulan kebutuhan secara detail untuk menspesifikasikan apa saja kebutuhan dari perangkat lunak sehingga bisa dipahami sesuai dengan kebutuhan user. Setiap spesifikasi kebutuhan perangkat lunak pada tahapan ini harus didokumentasikan dengan baik.

\section{b. Desain}

Pada tahap ini mendesain program perangkat lunak dengan proses multi langkah termasuk arsitektur perangkat lunak, struktur data, prosedur pengkodean dan representasi antar muka. 


\section{c. Pengkodean Program}

Pada tahap ini perangkat lunak yang sudah selesai desain akan dilanjutkan dengan pengkodean program sesuai dengan alur rancangan program yang sudah di desain. Sehingga akan dihasilkan program aplikasi yang sesuai dengan desain tanpa ada error program.

\section{d. Pengujian}

Pada tahap ini fokus pada pengujian perangkat lunak yang sudah running dan sudah tidak ada error serta valid. Pengujian ini dijalankan agar memastikan perangkat lunak yang dihasilkan sesuai dengan yang diharapkan dan meminimalisir kesalahan (error).

\section{e. Pendukung (support) atau pemeliharaan (maintenance)}

Pada tahap ini terdapat kemungkinan suatu perangkat lunak yang sudah siap pakai error pada saat digunakan oleh user. Saat program di running pemeliharaan tetap harus ada, kadang akan muncul error yang belum terdeteksi pada saat pengujian. Proses pemeliharaan dilakukan untuk proses pengembangan perangkat lunak tanpa membuat perangkat lunak baru.

\subsection{Teknik Pengumpulan Data}

Teknik yang dignuakan oleh penulis dalam melakukan pengumpulan data adalah:

\section{a. Metode Observasi}

Dalam metode observasi ini penulis terjun langsung untuk mencari dan mengumpulkan data tentang informasi akademik dengan cara melakukan pengamatan terhadap masalah yang dihadapi disekolah secara offline.

\section{b. Studi Pustaka}

Metode penulisan ini penulis juga melakukan studi pustaka yaitu penelitian kepustakaan dengan mencari sumber-sumber yang relevan untuk mengumpulkan data dan informasi melalui buku, jurnal ilmiah dan materi lainnya yang sesuai dengan masalah objek penulisan agar data yang di dapat lebih lengkap dan jelas.

\section{HASIL DAN PEMBAHASAN}

\subsection{Analisa Kebutuhan}

Sistem Informasi Akademik secara online berbasis website ini berfungsi sebagai sistem yang dapat digunakan oleh siswa atau orang tua siswa, untuk mencari informasi akademik seperti data absensi dan data nilai tanpa harus datang ke sekolah menemui guru.
Berikut ini spesifikasi kebutuhan (system requirement) dari Sistem Informasi Akademik Sekolah Menengah Pertama berbasis Web:

\section{A1. Skenario Kebutuhan Halaman Guru :}

1. Guru dapat mengelola data nilai siswa

2. Guru dapat mengelola data absensi siswa

3. Guru dapat mencetak Laporan Rekapitulasi Nilai

4. Guru dapat mencetak Laporan Ledger Rapor

A2. Skenario Kebutuhan Halaman Siswa :

1. Siswa dapat melihat data absensi

2. Siswa dapat mencetak data nilai murni

3. Siswa dapat mencetak data nilai raport

4. Siswa dapat mencetak jadwal mata pelajaran

\section{A3. Skenario Kebutuhan Halaman Admin :}

1. Admin dapat mengelola master data guru dan staff

2. Admin dapat mengelola master data siswa

3. Admin dapat mengelola master data kelas, termasuk mapping siswa, mapping mata pelajaran, dan jadwal mata pelajaran

4. Admin dapat mengelola master data parameter tahun ajaran

5. Admin dapat mengelola master data mata pelajaran

6. Admin dapat mencetak Laporan Data Kelas Per Tahun

7. Admin dapat mencetak Laporan Data Siswa Per Kelas dan Per Tahun

8. Admin dapat mencetak Laporan Data Guru dan Staff

\subsection{Logical Record Structure (LRS)}

Logical Record Structure (LRS) adalah perubahan bentuk dari penggambaran ERD dalam bentuk yang lebih jelas dan mudah untuk dipahami. Penggambaran LRS hampir mirip dengan penggambaran normalisasi file, hanya saja tidak digambarkan symbol asterix (*) sebagai symbol primary key (kunci utama) dan foreign key (kunci tamu). Basis data bisa diartikan juga sebagai sekumpulan data yang disusun dalam bentuk beberapa tabel yang saling memiliki relasi [13].Atau gambaran yang menghubungkan antara objek yang satu dengan objek yang lain dikenal dengan hubungan antar entitas[14]. Perbedaan LRS dengan E- $R$ diagram adalah nama tipe record berada diluar kotak field tipe record ditempatkan. LRS terdiri dari link-link diantara tipe record [15]. Gambar 2 merupakan Logical Record Structure Sistem Informasi Akademik yang digunakan pada penelitian ini. 
E Nurelasari

Komputika: Jurnal Sistem Komputer, Vol. 9, No. 1, April 2020

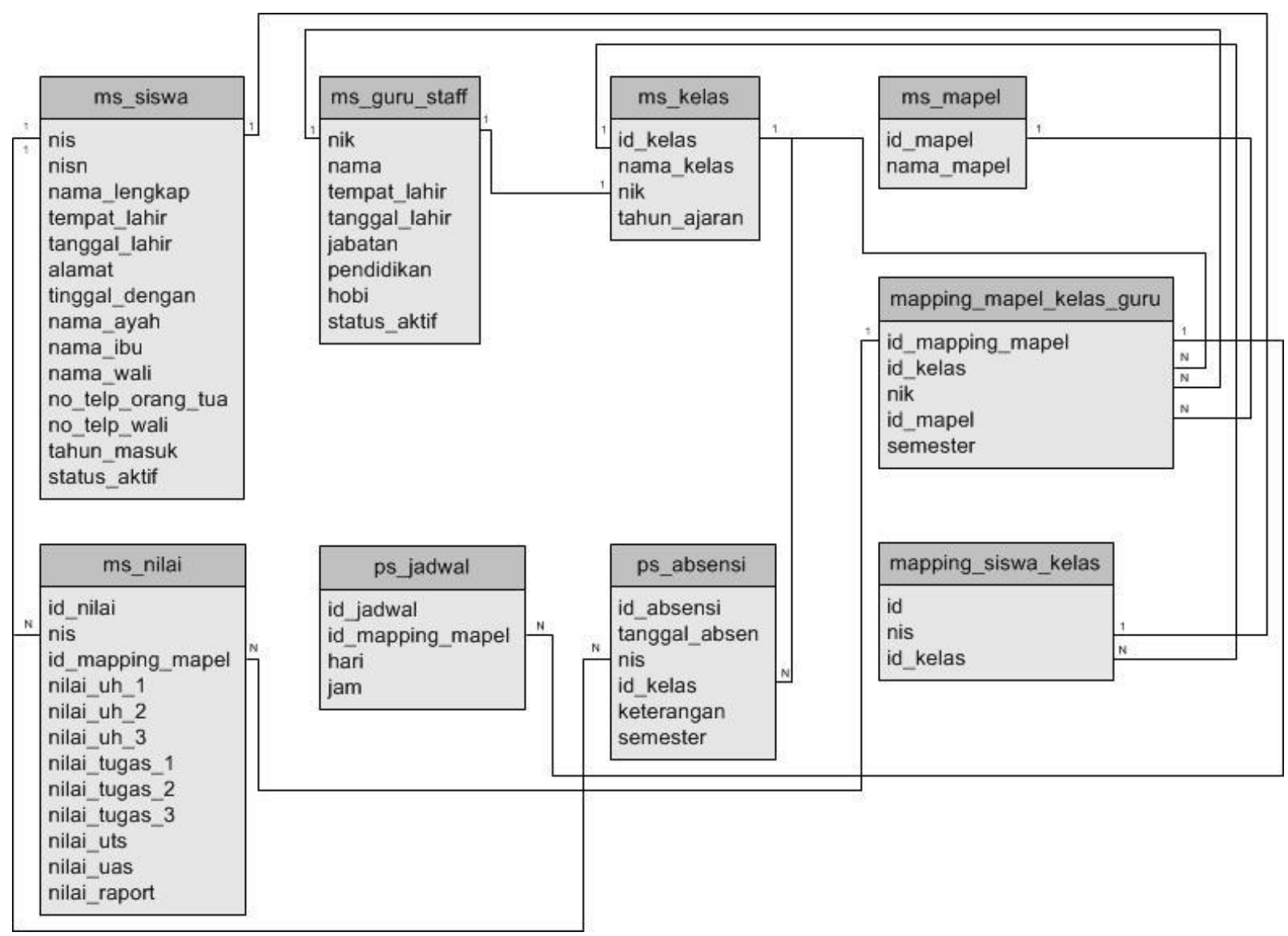

Gambar 2. Logical Record Structure Sistem Informasi Akademik

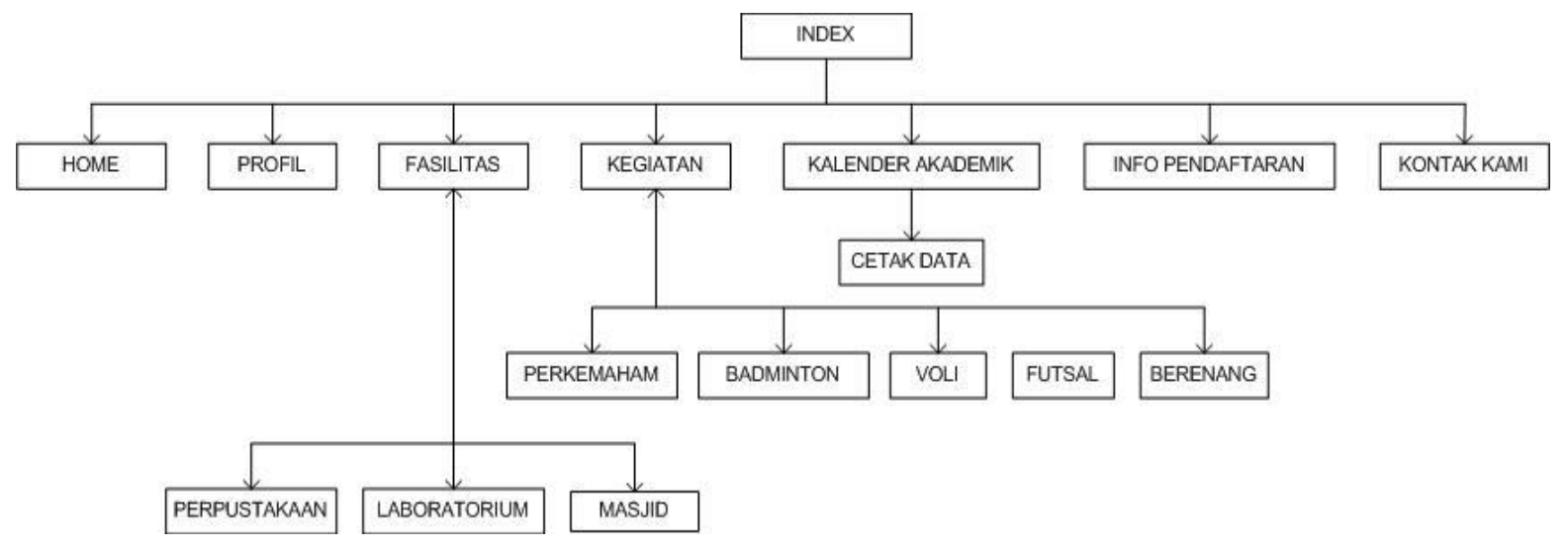

Gambar 3. Struktur Navigasi Index (Menu Utama)

\subsection{Spesifikasi Program}

Struktur Navigasi adalah urutan alur informasi yang diberikan untuk mengetahui secara garis besar sususan yang ada pada web ini secara menyeluruh.

Dalam sebuah pemrograman website diperlukan struktur navigasi sebagai bentuk penggambaran dari halaman-halaman apa saja yang tersedia di dalam website [15].

Berikut susunan struktur navigasi yang penulis buat pada web ini dapat dilihat pada gambar 3 :

\subsection{Tampilan Website}

Implementasi rancangan antar muka pada sistem informasi akademik berbasis web berdasarkan hasil rancangan antarmuka. 


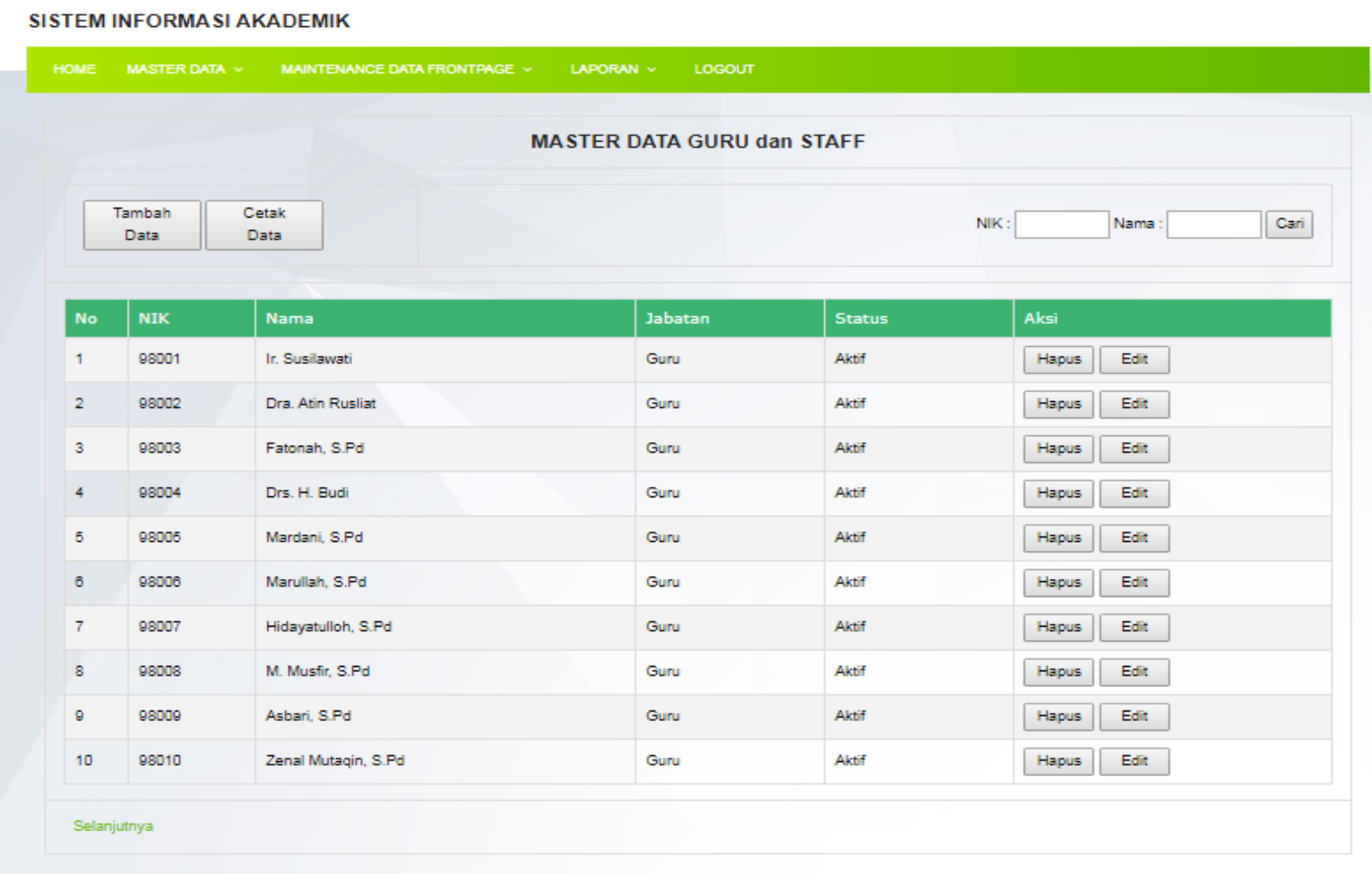

Gambar 7. Tampilan Menu Master Data Guru dan Staff

\section{A. Tampilan Menu Master Data Guru dan Staff}

Pada tampilan Menu Master terdapat seluruh data guru dan staff sekolah yang dapat ditambah, hapus, edit dan dicetak datanya oleh admin seperti yang diperlihatkan pada Gambar 7.

\section{B. Tampilan Halaman Home}

Tampilan Home dapat dilihat oleh seluruh masyarakat atau pengunjung tanpa harus melakukan login terlebih dahulu untuk mengetahui informasi-informasi sekolah seperti yang ditampilkan pada Gambar 4.

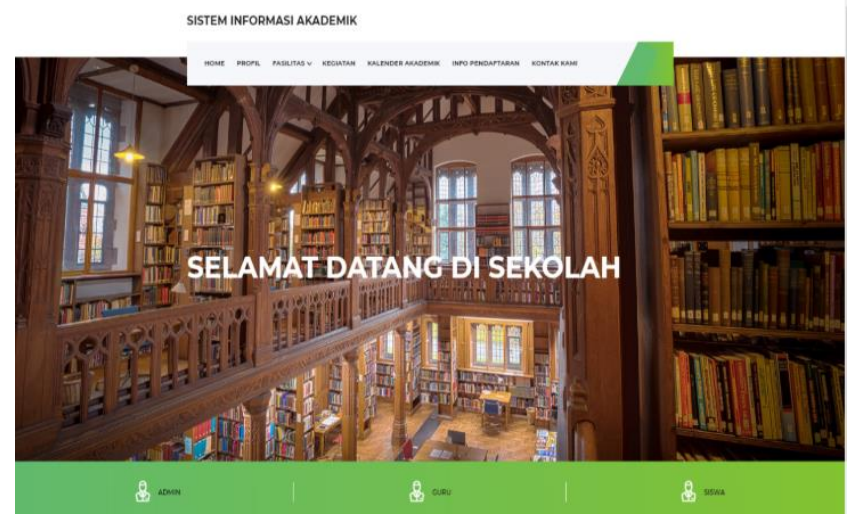

Gambar 4. Halaman Home

\section{Tampilan Halaman Login Guru}

Terlebih dahulu Guru harus melakukan login untuk dapat menggunakan menu-menu yang tersedia seperti pada tampilan Gambar 5. Apabila login berhasil dilakukan dengan sukses, maka menumenu yang sesuai dengan kategori guru akan ditampilkan.

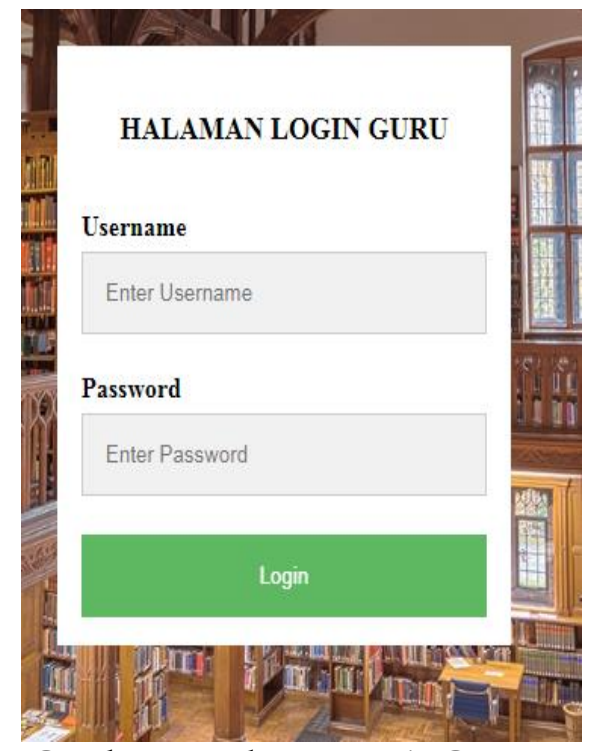

Gambar 5. Halaman Login Guru 


\section{Tampilan Halaman Login Admin}

Admin akan login terlebih dahulu melalui halama login seperti yang ditampikan pada Gambar 6 untuk bisa mengakses menu-menu yang tersedia. Setelah login akan masuk ke halaman admin untuk mengakses menu-menu admin.

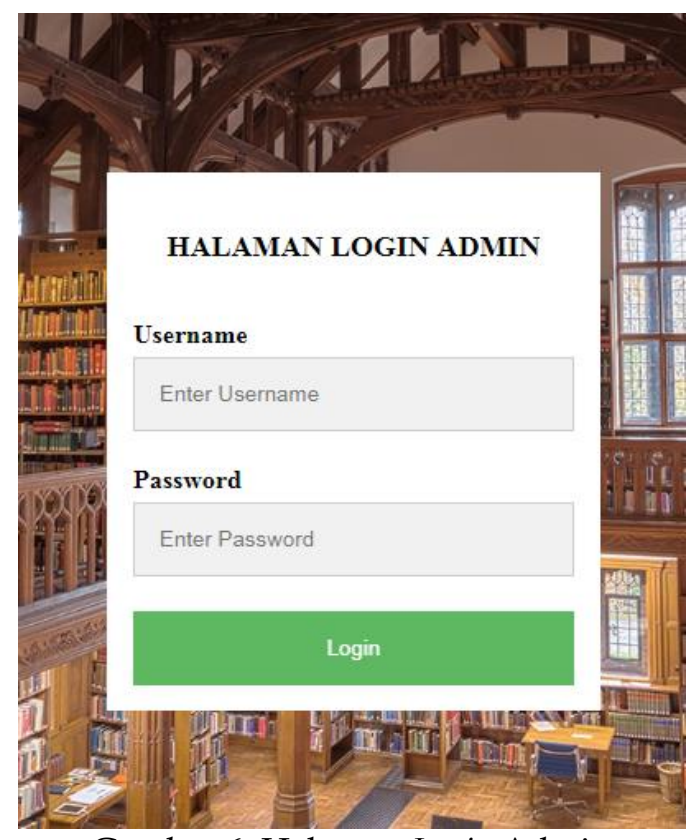

Gambar 6. Halaman Login Admin

\section{E. Tampilan Halaman Login Siswa}

Siswa login terlebih dahulu untuk masuk ke halaman akses siswa.

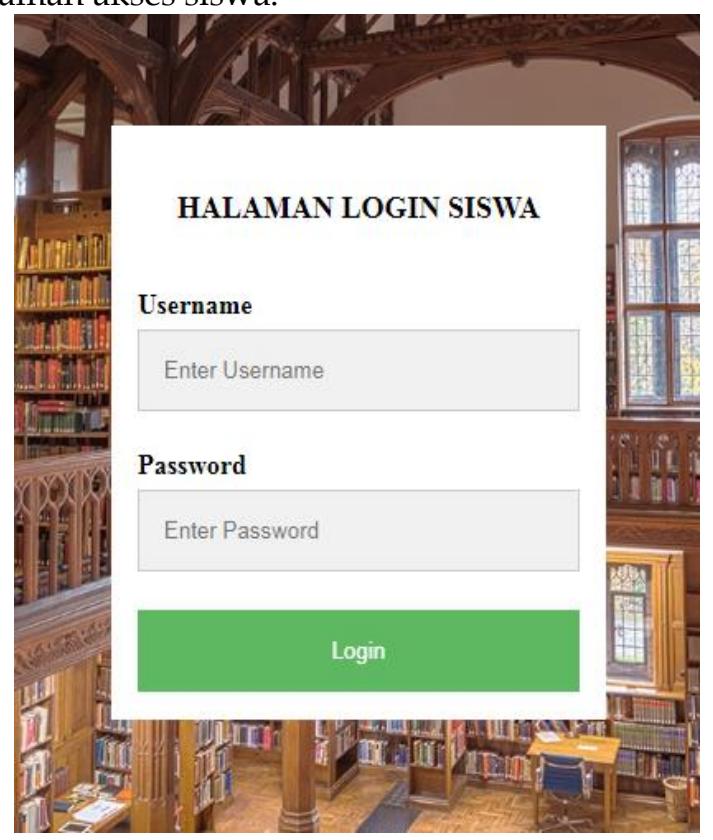

Gambar 8. Halaman Login Siswa

\subsection{Pengujian Unit}

Proses pengujian website sistem informasi dengan blackbox testing yang fokus terhadap proses input dan output pada web.
Tabel 1. Hasil Pengujian

\begin{tabular}{|c|c|c|}
\hline Fitur yang Diuji & $\begin{array}{l}\text { Hasil yang } \\
\text { diharapkan }\end{array}$ & $\begin{array}{l}\text { Kesim } \\
\text { pulan }\end{array}$ \\
\hline Form Login Guru & $\begin{array}{l}\text { Login berhasil dan } \\
\text { menampilkan } \\
\text { halaman home guru. }\end{array}$ & Valid \\
\hline Form Absen Siswa & $\begin{array}{l}\text { Sistem akan } \\
\text { menyimpan data } \\
\text { absen masing-masing } \\
\text { siswa sesuai dengan } \\
\text { pilihan keterangan } \\
\text { kehadiran. }\end{array}$ & Valid \\
\hline Form Input Nilai Siswa & $\begin{array}{l}\text { Sistem akan } \\
\text { menyimpan data nilai } \\
\text { siswa dan akan } \\
\text { menghitung nilai } \\
\text { akhir/nilai raport } \\
\text { yang didapat dari } \\
\text { nilai-nila yang diinput } \\
\text { tersebut. }\end{array}$ & Valid \\
\hline Form Login Siswa & $\begin{array}{l}\text { Login berhasil dan } \\
\text { menampilkan } \\
\text { halaman home siswa. }\end{array}$ & Valid \\
\hline $\begin{array}{l}\text { Halaman Menu Nilai } \\
\text { Murni }\end{array}$ & $\begin{array}{l}\text { Nilai Murni tampil } \\
\text { sesuai dengan nilai } \\
\text { yang diinput oleh } \\
\text { Guru. }\end{array}$ & Valid \\
\hline $\begin{array}{l}\text { Halaman Menu Nilai } \\
\text { Raport }\end{array}$ & $\begin{array}{l}\text { Nilai Raport tampil } \\
\text { sesuai rumus } \\
\text { perhitungan. }\end{array}$ & Valid \\
\hline $\begin{array}{l}\text { Halaman Menu Jadwal } \\
\text { Mata Pelajaran }\end{array}$ & $\begin{array}{l}\text { Menampilkan jadwal } \\
\text { mata pelajaran untuk } \\
\text { kelas yang dituju }\end{array}$ & Valid \\
\hline Halaman Login Admin & $\begin{array}{l}\text { Login berhasil dan } \\
\text { menampilkan } \\
\text { halaman home admin }\end{array}$ & Valid \\
\hline $\begin{array}{l}\text { Form Input Master } \\
\text { Data Guru dan Staff }\end{array}$ & $\begin{array}{l}\text { Data tersimpan sesuai } \\
\text { inputan }\end{array}$ & Valid \\
\hline $\begin{array}{l}\text { Halaman Menu Master } \\
\text { Data Siswa }\end{array}$ & $\begin{array}{l}\text { Data tersimpan sesuai } \\
\text { inputan }\end{array}$ & Valid \\
\hline $\begin{array}{l}\text { Halaman Menu Master } \\
\text { Data Kelas }\end{array}$ & $\begin{array}{l}\text { Data tersimpan sesuai } \\
\text { inputan }\end{array}$ & Valid \\
\hline
\end{tabular}

Hasil dalam pengujian pada Tabel 1 dapat berupa pernyataan:

a. Valid, diartikan bahwa fungsi fitur yang diuji telah sesuai dengan fungsinya.

b. Tidak Valid, diartikan bahwa fungsi fitur yang diuji belum berfungsi seutuhnya.

Berdasarkan tabel 1 menunjukkan semua fitur yang diujikan telah berfungsi dengan baik.

\section{KESIMPULAN}

Berdasarkan hasil pengujian dapat diambil beberapa kesimpulan bahwa Guru, Siswa, calon siswa maupun wali siswa dapat mengakses dengan mudah dan efisien. Penyajian Informasi sekolah yang meliputi data siswa, nilai siswa dan absen siswa. Disajikan dalam bentuk basis data yang dapat 
diupdate dimanapun. Dengan website ini, sekolah dapat meminimalisir penggunaan kertas karena pendataan dalam administrator dilakukan secara sistem komputerisasi.

\section{DAFTAR PUSTAKA}

[1] A. Fahrudin, B. Eka, P. Berliana, and K. Riasti, "Pembangunan Sistem Informasi Layanan Haji Berbasis Web Pada Kelompok Bimbingan Ibadah Haji Ar Rohman Mabrur Kudus," Sentra Penelit. Eng. dan Edukasi, vol. 3, no. 1, pp. 35-43, 2011.

[2] S. Ramadhan, S. Sarkum, and I. Purnama, "Sistem Informasi Penilaian Kinerja Pegawai Berbasis Web Pada Operasi Perangkat Daerah Kantor Camat Rantau Utara Labuhanbatu," Tek. Komput., vol. V, no. 1, pp. 93-96, 2019.

[3] R. W. Purnomo, "Pembangunan Sistem Informasi Pengolahan Data Pegawai Pada Sekolah Dasar (SD) Negeri Temon 4 Kecamatan Arjosari Pacitan," Indones. J. Netw. Secur., vol. 3, no. 4, pp. 44-51, 2014.

[4] E. S. Pane and M. Sadar, "Rancangan Website Sistem Informasi Akademik Sekolah Menengah Kejuruan (SMK) Negeri 5 Pekanbaru," J. Teknol. Inf. Komun. Digit. Zo., vol. 6, no. 2, pp. 33-41, 2015.

[5] N. Dengen and D. M. Kh, "Sistem Informasi Akademik Berbasis Web SMP Negeri 4 Samarinda," J. Inform. Mulawarman, vol. 4, no. 2, pp. 18-29, 2009.
[6] M. Susanti, "Perancangan Sistem Informasi Akademik Berbasis Web Pada SMK Pasar Minggu Jakarta," J. Inform., vol. III, no. 1, pp. 9199, 2016.

[7] S. J. Kuryanti, "Rancang Bangun Sistem ELearning Sebagai Sarana Pembelajaran," J. Khatulistiwa Inform., vol. 4, no. 1, pp. 84-92, 2016.

[8] M. Rahmayu, "Rancang Bangun Sistem Informasi Nilai Ujian Siswa SMP Negeri 3 Bumiayu Berbasis Web," J. Khatulistiwa Inform., vol. 3, no. 2, pp. 159-168, 2015.

[9] M. Hasbi, "Perancangan Sistem Informasi Akademik Pada Smk Negeri 2 Simbang Maros," J. Nalar Pendidik., vol. 3, no. 1, pp. 2-5, 2015.

[10] H. Jeperson, Konsep Sistem Informasi. Yogyakarta: CV Budi Utama, 2014.

[11] D. Maharani, "Perancangan Sistem Informasi Akademik Berbasis Web Pada Sekolah Islam Modern Amanah," J. Manaj. Inform. dan Tek. Komput., vol. 2, no. 1, pp. 27-32, 2017.

[12] R. A. Sukamto and M. Shalahuddin, Rekayasa Perangkat Lunak Terstruktur Dan Berorientasi Objek. Bandung: Informatika, 2018.

[13] C. A. Pamungkas, Pengantar dan Implemntasi Basis Data. Yogyakarta: CV Budi Utama, 2017.

[14] Y. Robi, Manajemen Basis Data Menggunakan MySql. Yogyakarta: CV Budi Utama, 2016.

[15] D. Andriansyah, Sistem Informasi Pendaftaran Event Dengan PHP Untuk Panduan Skripsi. Cirebon: CV ASFA Solution, 2016. 